\title{
CONSULTÓRIO LGBT: (RE)CONSTRUINDO NARRATIVAS DE COMBATE ÀS VIOLÊNCIAS LGBTFÓBICAS NA SAÚDE EM MACAÉ, RIO DE JANEIRO
}

\section{Paula Martins Sirelli' \\ Gabrielle Gomes Ferreira² \\ Ana Carolina Rodrigues Dias ${ }^{3}$}

Resumo: Este artigo é fruto de pesquisa realizada com o Consultório LGBT projeto desenvolvido no Consultório na Rua, serviço público de saúde da cidade de Macaé, Rio de Janeiro. Objetivamos publicizar e visibilizar esta experiência, compreendendo-a como fundamental na narrativa de combate às violências LGBTfóbicas, com enfoque na transfobia em contextos latino-americanos. A pesquisa qualitativa com profissionais e usuários do projeto ilustra a dificuldade de incorporar os ganhos materializados na Política Nacional de Saúde Integral LGBT, em especial por desinformação, conservadorismo e preconceito dos profissionais, além dos poucos investimentos da gestão municipal. $\bigcirc$ projeto Consultório LGBT contrapõe a histórica violação de direitos e a violência institucional no Sistema Único de Saúde.

Palavras-chave: LGBTfobia; saúde; conservadorismo.

\begin{abstract}
This article is the result of research carried out with Consultorio LGBT, a Project developed in the Consultório na Rua, a public health service in the city of Macaé, Rio de Janeiro. Our aim was to report on this experience that is essential for the narrative to combat LGBTphobic violence, particularly regarding transphobia in Latin American contexts. Qualitative research with professionals and users illustrates the challenges of incorporating the gains materialized in the Politica Nacional de Saúde Integral LGBT, especially due to the lack of information, conservatism and prejudice of professionals, in addition to the few investments made by municipal management. The Consultorio LGBT project goes against the historic violation of rights and institutional violence in SUS.
\end{abstract}

Keywords: LGBTphobia; health; conservatism.

Doutora em Serviço Social pela Universidade Estadual do Rio de Janeiro, Brasil. Professora do curso de Serviço Social da Universidade Federal Fluminense, Brasil. E-mail: paulasirelli@yahoo.com.br. Orcid: 0000-0002-3573-6283

2 Mestre em Serviço Social pela Universidade Federal Fluminense, Brasil. Doutoranda em Serviço Social pela Universidade Federal do Rio de Janeiro, Brasil. Assistente Social da Prefeitura Municipal de São Pedro da Aldeia (RJ), Brasil. E-mail: asgabrielleferreira@gmail.com. Orcid: 0000-0003-3338-8761

3 Bacharelem ServiçoSocial pelaUniversidadeFederalFluminense, Brasil.E-mail:ana_rodriguess13@hotmail.com. Orcid: 0000-0002-5854-1526 


\section{Introdução}

O Consultório LGBT da cidade de Macaé (RJ) é uma experiência inovadora no atendimento de pessoas LGBTs, como uma das respostas públicas no combate à LGBTfobia com enfoque na transfobia ${ }^{4}$. As reflexões que seguem objetivam visibilizar e publicizar esta experiência, compreendendo tal iniciativa como fundamental na narrativa de combate às violências nos contextos latino-americanos.

Localizada no norte do Rio de Janeiro, Macaé apresenta peculiaridades em relação às demais cidades da região no que se refere ao seu alto e rápido desenvolvimento econômico. Isso se deu pela instalação da Petrobras no município, trazendo a exploração do petróleo e transformando a cidade interiorana em uma capital nacional do petróleo.

Segundo dados do Instituto Brasileiro de Geografia e Estatística (IBGE, 2010), no censo demográfico de 2000 a 2010 Macaé apresentou um salto populacional de 132.461 para 206.728 habitantes. Esse boom teve ligação direta com a migração em busca de oportunidades de emprego, visto que a cidade era considerada um "El Dorado". Porém, a força de trabalho absorvida não só pela Petrobras, mas também por outras empresas atraídas por ela que se instalaram em Macaé, necessitava de qualificação. Nesse bojo, um número significativo de pessoas não foi incorporado ao quadro de trabalhadores da Petrobras nem das demais empresas, tendo que partir para a informalidade, chegando a ficar em situação de rua. Observou-se a presença de muitas mulheres trabalhando como profissionais do sexo.

O Consultório na Rua surge em Macaé em 2010, através da luta e organização de profissionais da rede pública, ao observar a quantidade cada vez mais expressiva de pessoas em situação de rua na cidade. Este número pode indicar a urgência de uma instituição capaz de estabelecer um diálogo mais direto com a população-alvo. A princípio, o Consultório na Rua começou a funcionar com um quadro pequeno de profissionais, e a partir do concurso público de 2012 novas pessoas foram incorporadas à equipe, o que qualificou o trabalho e trouxe múltiplos olhares. Nos dias atuais, a equipe conta com dois assistentes sociais, dois clínicos-gerias, um psiquiatra, uma enfermeira, uma técnica em enfermagem, uma psicóloga, duas cuidadoras e estagiários.

4 Destacamos o enfoque para a transfobia, pois apesar do Consultório LGBT atender todo a população LGBT, as pessoas transexuais e travestis, são o público que mais acionam o serviço. Como também todos as/os usuárias/ os entrevistada/os nesta pesquisa são transexuais. Entendemos que a LGBTfobia, portanto, engloba também os processos de preconceito e violência a população transexuais e travestis por isso utilizamos essa terminologia. 
mapeamento da cidade feito por tais profissionais permitiu reconhecer um território marcado pela atuação de transexuais e travestis ${ }^{5}$ como profissionais do sexo. Ao estabelecer vínculo com essa população, a equipe pôde identificar que as demandas se diferenciavam daquelas apresentadas ao Consultório na Rua, sendo mais específicas e exigindo atenção especializada. A partir dessa leitura, a médica psiquiatra, que era gerente da atenção básica na época, propôs o desdobramento da equipe no que veio a ser o projeto Consultório LGBT. Ela apresentou a proposta ao Conselho Municipal de Saúde, e as atividades tiveram início em 2016.

Trata-se de um trabalho pioneiro não só na região, como no estado do Rio de Janeiro, que tem atraído usuárias/os lésbicas, gays, bissexuais, travestis e transexuais (LGBTs) das cidades do entorno, o que denuncia uma lacuna no atendimento em saúde dessa população. Em Macaé, somente o programa de Infecções Sexualmente Transmissiveis (ISTs/aids) ${ }^{6}$ promovia ações específicas para esse público. $\bigcirc$ projeto Consultório LGBT ampliou - leque de intervenção com auxilio de uma equipe multiprofissional desde o acolhimento, oferecendo atendimento social, orientações médicas, eventos que promovem discussões sobre sexualidade e identidade de gênero, acompanhamento clínico, inclusive para uso hormonal.

Para visibilizar e publicizar esta experiência, estruturamos o artigo em três seções, objetivando apresentar problematizações e reflexões teóricas que contribuam para análises acerca do combate à LGBTfobia em diferentes contextos regionais, a partir da experiência de Macaé (RJ).

Na primeira seção, apresentaremos as perspectivas de organização política e homossexualidade no Brasil, compreendendo que o cenário vivenciado hoje no que tange à política de saúde brasileira é fruto de um reconhecimento - em si e para si - e de uma luta, portanto, de uma organização histórica de sujeitos, movimentos sociais e profissões em diferentes niveis de partcipação. No segundo ponto trataremos dos aspectos referentes aos profissionais do Sistema Único de Saúde (SUS) e à Política Nacional de Saúde Integral LGBT (PNS-LGBT). Por fim, apresentaremos os dados da pesquisa realizada no Consultório LGBT com profissonais e usuárias transexuais e travestis do serviço. Nossas análises buscam compreender como

\footnotetext{
5 Segundo o Caderno 4 do CFESS (2016b), que discute transfobia, usam-se pronomes femininos para designar as travestis, pois trata-se de uma identidade feminina, embora muitas delas não desejem realizar a cirurgia de redesignação sexual.

6 A sigla DST foi substituída por IST para destacar a possibilidade de uma pessoa ter e transmitir uma infecção, mesmo sem sinais e sintomas. Mais informações, disponíveis em: www.aids.gov.br/pt-br/publico-geral/o-que-sao-ist.
} 
se organizam as ações de combate à LGBTfobia e de que maneira essa iniciativa tem contribuído para a construção de respostas no âmbito estatal.

Realizamos, além da pesquisa bibliográfica, entrevista semiestruturada com três profissionais e quatro pessoas transexuais do Consultório LGBT. A pesquisa qualitativa foi importante para ilustrar a dificuldade de incorporar os ganhos materializados na PNS-LGBT no dia a dia dos serviços de saúde, em especial por desinformação e preconceito dos profissionais, bem como pela falta de investimento da gestão municipal em ações que qualifiquem o atendimento à população LGBT. Também foi possível compreender a inserção de usuários na rede de saúde de Macaé, evidenciando que as principais causas da descontinuidade no atendimento são o preconceito e a discriminação sofridos em diferentes serviços.

Vale ainda ressaltar um importante elemento deste estudo: uma vez que o Consultório LGBT compõe a rede da política pública de saúde, esta pode ser compreendida como espaço que abriga contradições, atuando tanto como aliada no combate à LGBTfobia, quanto como reprodutora das violações e violências no cotidiano de atendimento à população LGBT.

Esperamos que as reflexões apresentadas possam contribuir para publicizar dados e experiências reais de combate à violência contra LGBTs, situando a realidade do Consultório LGBT e da cidade de Macaé (RJ) enquanto uma possibilidade de repensar os rumos das respostas públicas e das iniciativas profissionais em um contexto de continuidade do serviço.

\section{Perspectivas de organização política e a homossexualidade no Brasil: a saída do armário em direção à cena pública}

Analisar a historicidade da organização LGBT pressupõe compreender como essa população se configura, de que modo se coloca na cena pública, e quando essas pessoas se reconhecem enquanto seres políticos por meio de sua luta e organização; ou seja, é necessário resgatar a historicidade de sua luta.

A realidade dessa população na atualidade contém particularidades impensáveis nas décadas anteriores. Nos últimos anos, pode-se ver o mercado se apropriar das pautas do movimento para transformá-las em mercadoria. Cabe destacar que isso não configura a inexistência do preconceito, da severa negação de direitos e da falta de investimento em política pública, muito pelo contrário: aponta uma estratégia de apropriação mercantil das 
demandas, que visa desmobilizar a luta por uma sociedade mais igualitária a qual não pode se realizar dentro dos marcos do capitalismo.

Essa condição traz uma falsa ideia de aceitação social ou de que a discriminação já não é preocupante, visto que LGBTs estão à frente de campanhas publicitárias, em novelas e/ou capas de revista. Segundo Almeida (2018, p. 162), "nossos corpos estão assim, desde sempre, imersos nos limites da cultura à qual pertencemos, uma cultura somática totalmente atravessada pelos nossos pertencimentos de classe social, raça, gênero, geração, entre outros".

Viver, ser e existir, para LGBTs, são formas de resistir politicamente, e isso se apresentou de modos diferenciados de acordo com o contexto histórico. A tomada de consciência para organizar uma luta por reconhecimento e igualdade de direitos foi influenciada por um movimento internacional, mais precisamente norte-americano, nos Estados Unidos (EUA).

A emblemática Revolta de Stonewall, de 28 de junho de 1969 em Nova York (EUA), ocorreu num contexto de forte repressão policial, ódio e intolerância ao universo de pessoas LGBTs, como também de negros e grupos sociais que não se "encaixavam" na normativa heterossexual, masculina e branca estadunidense da década de 1960. Essa revolta eclodiu dentro do Stonewall Inn, popularmente conhecido como "bar gay", onde lésbicas, gays, travestis e Drag Queens resolveram dizer não à opressão, à violência policial, às leis que feriam suas existências e os estigmatizavam.

Esse episódio foi o início do reconhecimento enquanto sujeitos coletivos, que, assim como as pessoas heterossexuais, deveriam ter direitos, poder de decisão e voz. $\bigcirc$ produto daquele momento histórico, o embate entre LGBTs e policiais, reverberou no país a ponto de diversos níveis do poder público repensarem os direitos dessa população, influenciando não só os Estados Unidos, como também outros países. Por esse motivo, o dia 28 de junho tornou-se o Dia Internacional do Orgulho LGBT. Nenhum direito foi adquirido sem luta e resistência.

No Brasil, Carvalho e Carrara (2013) defendem que a organização teve sua especificidade mesmo com a forte influência internacional, pois se deu por meio de um protagonismo masculino. A luta deu seus primeiros passos através da mobilização de homens gays cisgêneros, que reivindicavam direitos, melhores condições de abordagem social da sexualidade e cuidados com a saúde. Esta última era a pauta que demandava mais atenção, pois 
A explosão da epidemia de AIDS, no entanto, no final dos anos 1980, atingiu em cheio essa comunidade. Muitos grupos se desmobilizaram, enquanto outros passaram a se dedicar exclusivamente ao combate à doença, conhecida então, erroneamente, como - peste gay. No total, foram necessários 15 anos para que essa população fosse às ruas com força para exigir seus direitos a plenos pulmões. Entre 1995 e 1997 surgiram as primeiras Paradas do Orgulho LGBT [...]. (RIBEIRO, 2011, p. 155).

Facchini e França (2009) apontam o grupo Somos - que ainda não contava com uma expressiva participação trans, formado em sua maioria por homens gays cisgêneros - como o primeiro a enxergar esses sujeitos enquanto corpos políticos. O Somos foi fundado em São Paulo no final dos anos 1970, período marcado por uma conjuntura repleta de repressão aos que fugiam dos padrões conservadores da época.

Porém, as mobilizações paralelas que aconteciam no Brasil em prol dos direitos das mulheres, da liberdade de expressão artística, do movimento estudantil, de negras/os - que sobretudo reivindicavam a retomada da democracia, contra a censura - serviram como trampolim para encorajar os homens gays a lutar contra os paradigmas sociais e cobrar do Estado a elaboração de políticas públicas que atendessem às suas demandas, principalmente as ligadas à saúde sexual.

$\mathrm{Na}$ década de 1980, sob os efeitos da epidemia de HIV, um desafio se põe à luta dos LGBTs: enfrentar a esteriotipização. Alguns setores da sociedade associaram todas as pessoas homossexuais a vetores da doença. Por esse motivo, iniciativas como o Grupo Gay da Bahia (GGB), fundado em 1980 em Salvador, e o Triângulo Rosa, fundado em 1985 no Rio, tomam para si a responsabilidade de criar estratégias para enfrentar os preconceitos a fim de transformar o imaginário social construído (FACCHINI; FRANÇA, 2009).

Foi por meio desse esforço político coletivo, e com a abertura do diálogo com o Estado, que em 1985 a homossexualidade - até então definida enquanto homossexualismo, relacionada a uma patologia - é retirada do Código de Saúde do Instituto Nacional de Previdência Social (Inamps), que classificava a homossexualidade como "desvio e transtorno sexual". Esse foi um ato do Conselho Federal de Medicina em resposta às reivindicações do movimento de homossexuais. Internacionalmente, essa mudança só ocorre nos anos 1990, com a retirada da homossexualidade da Classificação Internacional de Doenças (CID). 
Carneiro (2015) aponta que essa conquista foi possivel graças a inúmeras manifestações e à pressão de ativistas, o que movimentou inúmeros agentes, desde a sociedade civil até representantes da macropolítica. Isso foi determinante para inserir/ampliar o debate sobre a aceitação de uma sexualidade dissidente da heterossexual.

Outra conquista apontada por Facchini e França (2009) um intenso debate proposto por ativistas acerca da inclusão da garantia de não discriminação por orientação sexual na Constituição Brasileira - a qual não deixa explícita, mas ensaia a ideia de que todos são iguais e por isso não se tolera nenhum tipo de discriminação no país.

Esse novo posicionamento do Estado auxilia a incorporação de novos sujeitos na luta, saindo do eixo principal - que era a região Sudeste - e se espalhando por todo o país. No governo Collor, nos anos 1990, o qual cria estratégias para inserir um modelo neoliberal no Brasil, assistimos a um paralelismo: enquanto o Estado começa a identificar essas pessoas como sujeitos de direito, o mercado as reconhece como nicho. É importante o regaste feito por Facchini e França (2009) acerca do termo Gays, Lésbicas e Simpatizantes (GLS), identificando a tentativa do mercado de se aproximar do grupo LGBT para formar este nicho lucrativo.

Destacamos que até então as reivindicações das travestis e das pessoas transexuais não tinham espaço dentro da luta de homossexuais, ainda que também fossem pessoas estigmatizadas pela sociedade. Entretanto, essa realidade muda completamente com o advento da epidemia do vírus HIV; houve uma pressão em prol da mobilização de pessoas, principalmente das travestis. Segundo Carvalho e Carrara (2013), este segmento já se organizava politicamente, ainda que muito mais para se autoproteger enquanto grupo de pessoas mais expostas a violências - seja pelo Estado (repressão policial), seja pela sociedade (ações de cunho preconceituoso).

A demanda ligada à saúde era a mais latente e emergencial. Ressaltamos uma personalidade de extrema importância para a luta das travestis, ainda em finais dos anos 1980: Brenda Lee, uma travesti que assumiu a responsabilidade do Estado no que diz respeito à proteção e prevenção de saúde. Ela

passou a acolher em sua casa os chamados - pacientes sociais, ou seja, aqueles que, embora não necessitassem de internação hospitalar, não tinham condições de exercer uma ocupação profissional e careciam de cuidados médicos diários. A maioria era de travestis soropositivas elou vítimas de violência. Inicialmente chamada de Palácio 
das Princesas, a casa passa a se chamar, em 1986 Casa de Apoio Brenda Lee [...]. (CARVALHO; CARRARA, 2013, p. 325).

Carvalho e Carrara (2013) apontam o ano 1992 como marco de tomada de consciência política pública. Naquele momento, um grupo de travestis que se prostituía na Praça Mauá (RJ) se reuniu no Instituto Superior de Estudos da Religião (ISER) para construir o que viria a ser a maior organização política dessa população na América Latina e a segunda maior do mundo. A Associação das Travestis e Liberados do Rio de Janeiro (Astral) surge como uma estratégia de enfrentamento dessa população à repressão policial. A organização de travestis e transexuais se dá de fato influenciada pela epidemia do vírus HIV. Entretanto, esse episódio publicizou a possibilidade de essas pessoas enxergarem suas demandas para além de questões de saúde; proporcionou que elas se enxergassem enquanto potência política.

O relativo sucesso em suas primeiras ações teria sido um motivador para as integrantes da ASTRAL organizarem, ainda em 1993, na cidade do Rio de Janeiro, o primeiro Encontro Nacional de Travestis e Liberados, que viria a se chamar ENTLAIDS, sob o slogan Cidadania não tem roupa certa. Este encontro contou com 95 participantes de cinco estados. A partir dele surgiram outras organizações, como o Grupo Esperança em 1994, em Curitiba; a Associação das Travestis de Salvador (ATRAS) em 1995; o grupo Filadélfia também em 1995, em Santos; o grupo Igualdade, em Porto Alegre; e a Associação das Travestis na Luta pela Cidadania (Unidas), de Aracajú, ambos em 1999. (CARVALHO; CARRARA, 2013, p. 328).

É nesse bojo, ao enfrentar os diversos desafios postos pela sociedade brasileira, que a luta das travestis ganha visibilidade. $\bigcirc$ movimento que antes era exclusivamente para homens gays cisgêneros ganha mais siglas e se desenha de forma ampla e complexa como LGBT. Vale destacar que, embora atualmente existem novas nomenclaturas, nos documentos públicos oficiais do Brasil (legislações, normativas e decretos) a sigla utilizada até o momento é a LGBT.

No que tange aos avanços históricos, a temática da saúde - que hoje abarca a iniciativa do Consultório LGBT - sempre atravessou o cotidiano das pessoas LGBTs. E, não por acaso, foi nessa área que tal população obteve mais conquistas. Atualmente pode-se constatar avanços nas políticas de promoção e prevenção em saúde da população LGBT no país. Isso é produto da tomada de consciência política dos sujeitos que compõem a luta 
pela não discriminação por identidade de gênero e/ou orientação sexual. Uma dessas vitórias se materializou na Portaria $n^{0} 1.820$, de 13 de agosto de 2009 (BRASIL, 2009), que versou sobre o direito ao uso do nome social no cartão do SUS.

Referente ao respeito pela identidade de gênero de usuárias/os do SUS, destacamos também a Portaria $n^{0} 2.803$, de 19 de novembro de 2013, que redefine e amplia (substitui a $n^{0} 1707 / 2008$ e a $n^{0} 457 / 2008$ ) o Processo Transexualizador no SUS. Há uma discordância por parte dos militantes, visto que esse direito foi viabilizado por meio de uma concepção da transexualidade como patologia, por isso atualmente se trava uma luta pela despatologização, mas com a necessidade de ratificar a responsabilidade do Estado de manter esse procedimento no sistema público de saúde.

É válido ainda destacar criação do programa intitulado "Brasil sem Homofobia" em 2004. Ele "foi desenvolvido com o objetivo de promover a cidadania e os Direitos Humanos à população LGBT a partir de equiparação de direitos e do combate à violência e à discriminação" (HOFFMAN, 2016). O "Brasil sem Homofobia" também traz apontamentos para a política de saúde, numa perspectiva que possibilite um atendimento qualificado das pautas de pessoas LGBTs.

Outra medida importante foi a realização da $1^{a}$ Conferência Nacional de Políticas Públicas e Direitos Humanos LGBT em 2008. O produto dessa Conferência foi uma transformação jamais vista na saúde, tanto no que se refere às legislações, quanto ao atendimento dessa população nos serviços de saúde. Essa transformação do modo de encarar os corpos LGBTs, iniciada pelo governo Lula, resulta, já no governo Dilma, na criação da mais importante portaria relacionada à saúde da população LGBT: a Portaria $n^{0}$ 2.836, de $1^{\circ}$ de dezembro de 2011, que institui no SUS uma política nacional de atendimento integral da população LGBT.

Vale destacar um ponto importante sobre os avanços conquistados nos direitos e nas políticas públicas de saúde para a população LGBT: todos foram concebidos a partir do governo do Partido dos Trabalhadores (PT). Assim, as reivindicações da população LGBT saem da parcial invisibilidade e adquirem espaço na cena pública. Parcial porque, como elucidam Mello, Brito e Maroja (2012), a primeira experiência - ainda que extremamente tímida - de construção de políticas públicas voltadas à população LGBT foi o Programa Nacional de Direitos Humanos 2 (PNDH 2). Amplamente divulgado pelo então presidente Fernando Henrique Cardoso, dentre suas 518 propostas 
de ações, cinco consideravam a "orientação sexual como uma dimensão da garantia do direito à liberdade, opinião e expressão" e dez estavam relacionadas à "garantia do direito à igualdade de Gays, Lésbicas, Travestis, Transexuais e Bissexuais - GLTTB" (MELLO; BRITO; MAROJA, 2012, p. 47).

Atualmente vivenciamos no Brasil uma conjuntura de reacionarismo conservador que afeta diretamente a existência de pessoas LGBTs. No bojo reacionário da sociedade brasileira, tendo como principal mentor o presidente eleito nas eleições de 2018, observa-se um cenário de regressão nos direitos LGBTs. Uma das principais pautas da presidência é a defesa do programa "Escola Sem Partido", apresentado na Câmara dos Deputados pelo Deputado Izalci (PSDB/DF) em formato de projeto de Lei n 867/2015. O programa "Escola Sem Partido" sugere a perseguição de professoras/ es, independentemente do nivel de ensino, que promoverem debate sobre gênero e sexualidade em sala de aula. É um ataque à liberdade de expressão e um retrocesso no campo dos direitos humanos. Basicamente, trata-se de proibir a discussão de temáticas sobre identidade de gênero, sexualidade, em prol de uma neutralidade do pensamento.

Tais políticos, com fortes vínculos religiosos e financeiros, apoiados por uma parte da população, afirmam que os espaços educacionais da atualidade fazem uma espécie de doutrinação da consciência, influenciados pelas pautas de partidos/militantes de esquerda. Também afirmam existir uma ideologia de gênero como ferramenta usada por professoras/es para influenciar crianças, adolescentes e jovens a se "tornarem" homossexuais/travestis/transexuais. Pode-se perceber que o cenário nebuloso que se desenha representa um abrupto retrocesso nas discussões democráticas sobre gênero e sexualidade no Brasil. Por isso é importante reafirmar que a história é processual, pois as conquistas evidenciam que os processos de luta são necessários.

Ressaltamos que, no início de 2019, foi anunciado como uma das primeiras ações do governo de Jair Messias Bolsonaro o fim das campanhas específicas de prevenção às IST/aids; e de lá para cá muitos outros ataques já vem se materializando. Por esse motivo, é necessário resgatar e trazer à luz da memória importantes avanços provenientes da organização política da população LGBT, mas também cobrar um novo posicionamento do Estado.

Marcados pela abertura de diálogo com os movimentos sociais, os governos dos petistas Lula e Dilma, que chegaram à presidência do Brasil com apoio da classe trabalhadora, foram pioneiros em encarar LGBTs 
enquanto sujeitos de direito, cidadãs/os que tinham necessidades para além daquela ligada à prevenção do HIV/aids.

Como adendo à discussão evocamos Cassin (2016), cuja análise aponta a conciliação de classe que foi peculiar aos governos petista, garantindo uma ampliação dos direitos sociais da classe trabalhadora brasileira - a qual pressionou o Estado por respostas imediatas - ao passo que agigantou o lucro do capital. É inegável, entretanto, que tais concessões significaram ampliação dos direitos para a classe trabalhadora e para a população LGBT.

\section{Profissionais do SUS e Política Nacional de Saúde Integral LGBT (PNS-LGBT)}

A Portaria 2.836/2011 regulamenta a PNS-LGBT e traz como fundamento legal o direito de todas/os à saúde, garantido no artigo 196 da Constituição Federal de 1988 e no $\S 1$ do artigo $2^{\circ}$, que trata das disposições gerais da Lei 8.080/1990 (a qual regulamenta o SUS) e dispõe sobre o dever do Estado de garantir o acesso universal e igualitário nos serviços de saúde (BRASIL, 2011).

Popadiuk, Oliveira e Signorelli (2017) explicam que o protagonismo do movimento LGBT nas ruas, junto com ativistas do movimento pela Reforma Sanitária - responsáveis por transformar o conceito de saúde pública no Brasil, na direção da construção de uma política pública universalizada e vista como direito de todas/os - e as reivindicações nos espaços de controle democrático como as Conferências e Conselhos de Saúde, foram imprescindiveis para que o Ministério da Saúde instituísse tal política.

Pode-se perceber que a proposta de construir uma política nacional de saúde voltada às necessidades da população LGBT não se concretizou sem enfrentar forças políticas contrárias; nenhuma conquista se dá sem luta. $\bigcirc$ ano de 2011 foi marcado pela ascensão do conservadorismo representado no legislativo pela bancada religiosa. Por outro lado, a luta de LGBTs também pressionou o governo a buscar respostas e reconhecer suas inúmeras demandas em saúde, de forma a ampliar os serviços ofertados.

Seguindo a proposta de descentralização político-administrativa adotada pelo SUS, a PNS-LGBT também vai designar responsabilidades e funções para cada esfera de governo. Assim fica estabelecido que os municípios são responsáveis por implementar a política, identificando as necessidades de saúde da população LGBT, bem como incentivando à construção de redes de serviços, a participação nos espaços de controle democrático 
(como Conselhos e Conferências de Saúde), e apoiando as lutas sociais ligadas à temática de sexualidade e gênero (BRASIL, 2013, p. 25).

A responsabilidade de implementar a política e de melhorar os serviços prestados à população LGBT pressupunha algumas orientações, já explícitas na lei, tais como a articulação com outros setores de políticas sociais. Dois parágrafos nos chamam a atenção na lei, a saber: "VI - incluir conteúdos relacionados à saúde da população LGBT, com recortes étnico-racial e territorial, no material didático usado nos processos de educação permanente para trabalhadores de saúde"; e o parágrafo VI: "implantar práticas educativas na rede de serviço do SUS para melhorar a visibilidade e o respeito a lésbicas, gays, bissexuais, travestis e transexuais" (BRASIL, 2013, p. 26). Estes destaques já mostram uma preocupação com a formação dos trabalhadores de saúde, de forma a construir estratégias de respeito às demandas desta população.

Vale destacar também o modo como ficou estruturado o Plano Operativo da PNS-LGBT durante o período de 2011-2015, que traçou estratégias federais, estaduais e municipais de ação no SUS, numa tentativa de qualificar o trabalho realizado oferecendo atendimentos contínuos à população LGBT, de modo a preconizar a integralidade dos serviços de atenção básica ou especializada, atrelado à qualidade de vida e promoção e prevenção em saúde. E mais uma vez, reafirma a necessidade de "incluir os temas orientação sexual e identidade de gênero nos processos de formação e educação permanente dos trabalhadores da saúde e no exercício do controle social", bem como "identificar, combater e prevenir situações de preconceito, discriminação, violência e exclusão nos serviços de saúde" (BRASIL, 2013, p. 28). terceiro eixo do Plano envolve ações em educação permanente e educação popular em saúde com foco na população LGBT, como forma de atualizar profissionais e gestoras/es inseridas/os no SUS, independentemente do cargo que ocupam.

É interessante notar que a todo o momento a própria política, construída por técnicos e representações da luta LGBT, traz uma preocupação com a formação continuada, com análise de dados para gerar novas possibilidades de intervenção profissional. Porém, pautar essas questões em caráter de política não garante a materialização desta. Empecilhos diretamente ligados ao tipo de sociabilidade vigente - embasada em produtividade, possibilidade nula ou quase nula de reflexão crítica acerca do trabalho profissional, ocasionada pela quantidade massacrante de afazeres, o que incentiva um pensamento individualista - necessitam ser analisados e superados coletivamente. 
Para além das condições materiais e cotidianas do trabalho profissional, há outros inúmeros desafios na materialização dessa política, impulsionados por distintas motivações. Dentre elas, pode-se destacar o padrão heteronormativo dos atendimentos, falta de acesso à informação/desconhecimento, religiosidade, patologização da homossexualidade e da transexualidade, conservadorismo e preconceito por parte dos profissionais de saúde.

$\bigcirc$ irracionalismo presente na sociedade do capital dispensa o pensamento crítico e a reflexão social, em nome de um praticismo da vida. Dessa forma, posições preconceituosas expressas através do moralismo perpetuam-se. As marcas deixadas pelo pensamento conservador cristão - que condiciona a posição de determinados setores da sociedade de acordo com sua sexualidade, gênero, raça/etnia, renda - ainda estão no ideário social (visto que são opressões necessárias para perpetuar a sociedade do capital) e impactam a forma de fazer o trabalho profissional. A desigualdade entre gênero e sexualidade tende a ser fomentada, reafirmando um padrão heteronormativo, porque está atrelada aos interesses da classe dominante.

Quando se fala de heteronormatividade nos atendimentos de LGBTs em instituições de saúde, significa que somente são consideradas relevantes as dimensões ligadas à vivência de mulheres e homens heterossexuais; logo, as pessoas que fogem dessa definição têm suas necessidades reprimidas e muitas vezes acabam não se sentindo confortáveis para falar abertamente da sua sexualidade, por temerem uma reação negativa das/os profissionais.

A legislação brasileira (PNS-LGBT e seu plano operativo) é bastante nítida no que concerne ao papel do Estado, nos seus diferentes âmbitos, de garantir a formação de profissionais e gestores/as no tocante às demandas da população LGBT. Cristalizar-se no argumento do "não saber", da "desinformação" pode descambar em posicionamentos antiéticos ou mesmo violadores e violentos à população LGBT.

Hamermüller (2016) aponta em sua pesquisa que, dentre 307 profissionais participantes, cerca de $70 \%$ nunca tinham ouvido falar de gênero e sexualidade - um dado alarmante, que reforça a necessidade de responsabilizar gestores/as para que forneçam às/aos profissionais a possibilidade de acompanhar as transformações da sociedade, através de um processo permanente de formação.

Mas não é apenas a desinformação que baliza a prática profissional: a mesma pesquisa aponta que, ao comparar posturas de alunos religiosos e não religiosos, não houve uma mudança significativa no nível de 
discriminação. Ou seja, qualquer profissional carrega em si valores cultivados por uma vida, inclusive religiosos. Historicamente, a homossexualidade e a transexualidade são condenadas, seja como patologia, seja como desvio de caráter individual ou religioso. Reproduzir tais perspectivas não é difícil.

Questionar certezas absolutas não é algo que acontece rapidamente; isso demanda das/os profissionais um despertar de consciência e tempo para que ideias tão arraigadas, que foram socialmente construídas, sejam substituídas por respeito ao desejo e à identidade da/o outra/o. Por esse motivo, a educação permanente tem de constituir uma parcela da discussão sobre a atenção integral à saúde, que, por sua vez, deve ser favorável ao contínuo contato com as diversas realidades existentes e em sintonia com a dinamicidade social (FONTENELE; REIS; FRIAS, 2015).

A dinamicidade de sociedade do capital e a negação de uma atualização ideocultural perante as transformações societárias sustentam um sistema de preconceitos que partem da irracionalidade presente no cotidiano, marcado pela não reflexão crítica, pelo individualismo e pelo senso comum, somados ao juízo de valor, incutindo na vida do/a outro/a aquilo que acredita ser o certo ou aceito.

A luta de pessoas LGBTs no campo da saúde ultrapassa os limites desta política; é histórica e marcada por conquistas e derrotas. Sem dúvidas, as questões ligadas à sexualidade humana e à identidade de gênero sempre estiveram presentes e acompanham o desenvolvimento da sociedade, ganhando espaço na cena pública, reivindicando direitos e evidenciando a sexualidade como uma expressão social.

A conjuntura brasileira não se apresenta favorável para discutir essa temática, pois é um cenário "de um caldo de cultura ultraconservadora, expressa em práticas fascistas e irracionalistas" que aponta graves violações de direitos da população LGBT. "Manifestações cotidianas de ódio e violência contra quem pensa e age de forma diferente relevam um cenário assustador e regressivo, do ponto de vista político e civilizatório, em que a intolerância e a discriminação marcam presença obrigatória" (CFESS, 2016a, p. 7). Os/as profissionais não ficam imunes a estas ideias e práticas, uma vez que

essas condições sociais interferem na vida cotidiana, na subjetividade dos indivíduos, em seus valores e sentimentos, reproduzindo ideias, hábitos, modos de comportamento, que motivam a sua inserção em ações e movimentos coletivos que podem ou não reforçar o preconceito. $\bigcirc$ trabalho profissional, como parte do cotidiano, não 
sendo imune a essa conjuntura, ainda conta com uma herança conservadora em sua trajetória. (CFESS, 2016a, p. 7-8).

O que se observa é uma tendência a reforçar esse preconceito. Uma pesquisa recente do Ibope constatou que o conservadorismo no Brasil cresceu de $49 \%$ em 2010 para $54 \%$ em 2016 e chegou a 55\% em 2018, no segmento de pessoas que fizeram faculdade. "O índice reflete a proporção de brasileiros que apoiam ou refutam cinco propostas: casamento de pessoas do mesmo sexo, legalização do aborto, redução da maioridade penal, prisão perpétua para crimes hediondos e adoção da pena de morte" (TOLEDO, 2018).

A pesquisa informa também que "cresceu a rejeição ao casamento entre pessoas do mesmo sexo (de 44\% para 50\%)" (TOLEDO, 2018). Para quem se posiciona contra, supostamente defendendo os valores da "família" - somente o modelo tradicional de família - e de "Deus", a população LGBT teria sido responsável por destruir tais valores. Desse modo, compreende-se o cenário altamente preconceituoso que se desenha no país e num conjunto de pessoas com acesso à instrução, graduadas e que possivelmente atenderão ou já atendem pessoas LGBTs. Por isso uma preocupação se faz urgente, diante desse contexto hostil à existência de pessoas LGBTs, que ainda enfrentam uma sociedade que não superou o preconceito, seja ele de raça/ etnia, gênero, ou sexualidade: pode-se perceber que vão encontrar desafios para acesso ao atendimento no SUS, um direito básico que deveria ser universal.

Reproduzir esta conduta no atendimento prestado por profissionais do SUS traz diferentes impactos para pessoas LGBTs, as quais enfrentam situações de extremo risco, como a autoaplicação de hormônios e silicone industrial, muitas vezes indicados em grupos de redes sociais voltados a esse assunto. Sem o acompanhamento de especialista, o uso indiscriminado de hormônios e a aplicação do silicone industrial podem levar ao desenvolvimento de doenças graves e até à morte.

Fica evidente o sofrimento dessas pessoas ao não se reconhecerem no corpo biológico e não poderem manifestar livremente sua sexualidade, o que desencadeia também em sofrimentos psíquicos como crises de ansiedade, depressão, sindrome do pânico e inúmeras tentativas de suicídio.

Garantir o acesso de pessoas LGBTs aos serviços de saúde implica conduzir o trabalho profissional com uma perspectiva ampla e complexa, para além da relação saúde-doença-cura, atentando às transformações da realidade social para fornecer estratégias de acolhimento, reconhecimento de 
novas demandas trazidas por LGBTs, e assim criar estratégias de formação continuada das/os profissionais em uma perspectiva crítica, a fim de qualificar o trabalho realizado nos espaços de saúde.

Esta não é uma tarefa de serviços específicos de atendimento à população LGBT, mas de gestores/as e profissionais de qualquer serviço. $\bigcirc$ que apresentaremos a seguir é uma construção coletiva de um grupo de profissionais que, tendo esta capacidade de analisar a realidade e suas transformações, adequou e transformou o serviço de saúde (e a si mesmos/as) em uma tentativa de responder de forma qualificada às demandas dessa população.

\section{Projeto Consultório LGBT em Macaé (RJ) e o combate à LGBTfobia}

O Consultório LGBT nasceu do compromisso de um conjunto de profissionais em dar respostas concretas a uma demanda contemporânea, que se materializou de forma bastante enfática em Macaé: atender a população LGBT, em especial pessoas transexuais e travestis. Para entender o processo de formação destes/as profissionais e a forma como a rede de saúde da cidade vem recebendo tais usuários/as, entrevistamos três profissionais dos seis que fazem parte de projeto Consultório LGBT, sendo: um assistente social, uma técnica em enfermagem e uma cuidadora, que se autodeclararam heterossexuais, com idade entre 41 e 42 anos. Duas dessas pessoas são evangélicas, e uma católica.

Foram entrevistadas/as ainda quatro usuárias/os referenciadas/os no projeto: três homens trans e uma mulher trans, com idade entre 14 e $21^{7}$ anos. Dessas quatro pessoas, duas se identificam como heterossexuais e duas como homossexuais.

Araújo et al. (2006) sugerem que as/os profissionais da saúde não estão preparadas/os para atender pessoas LGBTs, reproduzindo um padrão de atendimento heteronormativo, pois não consideram importantes as dimensões da sexualidade e identidade de gênero. Uma de nossas questões foi compreender se essa afirmação é verdadeira na cidade de Macaé. Em que medida as equipes de saúde estão preparadas para atender a população LGBT? E os/as profissionais do Consultório LGBT, têm uma perspectiva diferente?

Nesse sentido, as entrevistas tentaram perceber em que medida as/os profissionais reconhecem ou não esse preparo. As profissionais 1 e 2 (P1 e

7 Vale destacar que o projeto Consultório LGBT não tem como público crianças e adolescentes, mas as/os acolhe, faz as devidas orientações e as/os encaminha para uma instituição de referência. 
P2) ${ }^{8}$ apontam a defasagem sinalizada por Araújo et al. (2006) em sua formação. Isso fica explícito quando P1 afirma: "Eu tive o primeiro contato enquanto profissional com LGBTs quando surgiu o Consultório na Rua, e a partir da abordagem na rua com as travestis, profissionais do sexo".

P2 relata que a ausência de debate sobre $L G B T s$ tem impactos na forma de abordar e atender usuárias/os do serviço, gerando um processo de descriminação dentro dos espaços de saúde:

Mas eles/as [usuárias/os LGBTs] já trouxeram vários relatos, por exemplo, a primeira coisa que eles falam: na recepção, sendo homem ou mulher trans, e chamarem pelo nome de registro "Não, "to" perguntando seu nome, isso [nome social] pra mim não é nome!". Aí vem a "Mariana", mas chamam de "Tiago" e já passa aquele constrangimento desde ali [início]. As pessoas já ficam olhando e julgando. (P2).

É importante perceber que as/os profissionais entrevistadas/os reconhecem um direito que está sendo violado e que precisa ser garantido. Esta violação pode perpassar a via do desconhecimento, mas também o conservadorismo incutido entre profissionais de saúde. $\bigcirc$ desrespeito ao nome social é uma denúncia recorrente também de usuárias/os que chegam ao Consultório LGBT, o que pode indicar que as/os profissionais do município não estão sendo preparadas/os para lidar com este tipo de situação.

Todas/os as/os usuárias/os, que têm ou já tiveram plano de saúde, denunciaram algum tipo de discriminação não só dentro do SUS, mas também no sistema privado de atendimento à saúde. A discriminação e o desconhecimento das demandas de sexualidade e identidade de gênero foram determinantes para a descontinuidade dos atendimentos, como se percebe na seguinte fala:

Eu tinha plano de saúde da empresa $A$, eu fui em todos os endocrinologistas do plano de Macaé e nenhum me atendeu. Todos eles. Clínico-geral também não. Eles chegaram a me atender, foram super simpáticos, já tinha até começado a consulta. Mas, quando eu falei que era trans, a consulta acabou em 10 segundos, dizendo que não podiam fazer esse tipo de acompanhamento. E que eu só conseguiria no Rio, em Macaé jamais. E aí, foi quando eu abri mão de pagar o plano de saúde, procurei pelo público, vim direto pra cá e consegui aqui. (U1).

Essa fala revela o despreparo dos profissionais em diferentes instâncias para lidar com uma demanda cada vez maior de hormonioterapia. Revela

8 Para garantir o sigilo dos nomes, serão utilizadas formas genéricas como "profissional 1" (P1) e "usuária/o" (U1). 
também a importância do SUS, pois mesmo num serviço privado não foi possivel conseguir atendimento. As pesquisas e tecnologias desenvolvidas demonstram a amplitude do SUS e sua potencialidade enquanto política pública, bem como a capacidade de acompanhar a realidade e criar estratégias para responder demandas - a promulgação da PNS-LGBT reafirma isso. $E$ contraria o discurso falacioso que tenta difundir a ideia de que tudo que é público é ruim - discurso este que é parte de um projeto de sociedade que, através de cortes nos gastos sociais, quer desmantelar o SUS e transformá-lo em mercadoria.

Assim como U1 interrompeu o atendimento ao sofrer situações de preconceito, U4 se sentiu ofendida com a ação de uma profissional que "orou" o hormônio que ia aplicar nela, por isso não retornou aos outros atendimentos. Observamos a violência institucional a que estão submetidas/os tais usuárias/os, sendo o SUS muitas vezes um espaço violador ao invés de articulador no combate às LGBTfobias.

Estes relatos caminham na direção de apontar que o preconceito, a desinformação e o desconhecimento das demandas apresentadas a profissionais de saúde são determinantes para a descontinuidade dos atendimentos. Os reflexos de uma sociedade heteronormativa, conservadora e machista impactam diretamente a forma como LGBTs serão atendidas/os nos espaços múltiplos de saúde.

U3 já traz um depoimento mais grave, acerca de profissionais de diferentes formações do SUS e do sistema de saúde privado, que também se negaram a atendê-lo:

Fui atendido no SUS e pelo plano de saúde B, por psicólogos, psiquiatras, clínico-geral, neurologista, ginecologista e urologista. E todos os atendimentos foram péssimos, porque por exemplo, com psiquiatra ele não teve o mínimo esforço para pelo menos me escutar, ele simplesmente ignorou. Anotou meu nome social e só. E quando eu tocava no assunto de novo, ele falava alguma coisa do tipo: "Ah a sua cabeça tá confusa, você tá cheio de problemas, tal remédio serve pra isso". "E outros psicólogos fizeram parecido, ignoraram ou forçaram goela abaixo que eu era uma garota. O único atendimento decente, sem ser o daqui, que eu tive foi da minha ginecologista, quem me encaminhou para o projeto Consultório LGBT.

Esses relatos indicam que, independente da área, a desinformação e o preconceito perpassam formações distintas e, consequentemente, a intervenção de profissionais. Como pensar na saúde como um provável campo 
de acolhimento das demandas por assistência em saúde da população LGBT, aliada ao combate das LGBTfobias?

modelo de educação vigente e os conteúdos oferecidos pelos cursos de formação profissional não estão dissociados do tipo de sociabilidade em que estamos inseridas/os. $\bigcirc$ cotidiano capitalista é marcado pela alienação, com ascensão do discurso individualista e do moralismo condicionados pelo pensamento conservador burguês para ditar valores e padrões de gênero através de preconceito, estereótipos e discurso de ódio.

U2 relata ter passado pela mesma experiência, dessa vez no SUS:

Eu procurei o posto de saúde "Sal Sal" em Rio das Ostras -RJ, na época que morei lá, e procurei todos os endocrinologistas e clínico-geral da rede e nenhum quis me atender. Todos alegando que não faziam acompanhamento de pessoas transexuais, sendo que são endocrinologistas e podem fazer. Eles não fazem porque não querem fazer. (U2).

Esses relatos indicam uma realidade marcada por uma sequência de negação de direitos, desrespeito à sexualidade e identidade de gênero de usuárias/os LGBTs que denunciam posturas antiéticas e criminosas de profissionais dentro e fora do SUS. Posturas essas que impactam diretamente - acesso a uma política que preconiza a universalidade, impedindo a realização de um atendimento de saúde qualificado e causando sofrimento aos corpos que já são marginalizados. São posturas de uma violência institucional que corroboram um cenário de LGBTfobia.

Trata-se de uma expressão da própria sociabilidade vigente, ponto levantado por Cisne (2012). Para a autora, o pensamento conservador burguês dita os padrões de gênero aceitáveis ou não, o modo como homens e mulheres podem se expressar socialmente, aumentando assim a produção de opressões que moldam nossa sexualidade e identidade de gênero.

Diferentemente do que Hamermuller (2016) aponta em seu artigo, sobre o fato de profissionais religiosas/os serem extremamente preconceituosas/os e de nem mesmo depois do trabalho com pessoas LGBTs mudarem de pensamento, pudemos constatar que as/os profissionais inseridas/os no projeto Consultório LGBT, todas/os com uma vertente religiosa, afirmam ter ocorrido sim uma mudança considerável na vida profissional ou privada.

Mudança sempre há. Porque a gente olhava, assim de fora, a gente achava que era um pouco "pô, que sem vergonha, o cara quer 'virar' mulher?". Mas, depois que a gente vai conhecendo as pessoas, a gente vai vendo que realmente tem um sentimento ali, uma dor, 
um sofrimento. Por exemplo, ter um corpo de homem, mas se identificar enquanto mulher, é você sem sentir preso a um corpo que não é seu. (P1).

É importante reafirmar a iniciativa de formação continuada dos profissionais do Consultório na Rua, mostrando a possibilidade que esta ferramenta tem para desconstruir paradigmas e preconceitos, como evidenciam as falas dos próprios profissionais:

\begin{abstract}
Mudanças? Tiveram sim! Até mesmo um outro olhar, por mais que a gente seja profissional de saúde, mas a gente também traz os nossos valores, as nossas tradições religiosas. No meu caso, vindo de uma cidade do interior, há uma mudança de paradigma a partir do momento que a gente olha o sofrimento daquela pessoa você passar a ter uma outra visão, para além do senso comum. Aqui a gente se vigia mais para não se tornar igual a outros profissionais da rede que cometem infração de direito. (P3).
\end{abstract}

P1 e P2 afirmaram que fizeram o curso da Universidade Aberta do Sistema Único de Saúde (Unasus) e que conheceram lá a PNS-LGBT. A Unasus foi criada especialmente para fornecer processos de formação de profissionais do SUS. Todos os cursos são on-line e gratuitos. É importante que o SUS e as/os gestoras/es dos serviços de saúde proporcionem às/aos profissionais momentos de suspensão do cotidiano, como as horas de educação permanente, para que possam refletir sobre o trabalho profissional e assim, conseguir se atualizar diante das novas demandas e atores sociais.

A ousadia das/os profissionais do projeto Consultório LGBT demonstra um compromisso ético com a efetivação de direitos. Ainda que todas/os as/ os profissionais entrevistadas/os apresentem limitações, ligadas aos valores naturalizados por uma vida inteira, à ausência do debate de gênero e sexualidade na profissão e às próprias dúvidas, tais obstáculos foram superados por um anseio de acolher as demandas da população LGBT e assegurar direitos no combate a um cenário de LGBTfobia devastador em Macaé.

Consultório LGBT traça outra narrativa de atendimento à população LGBT nos serviços de saúde, uma narrativa que se contrapõe à histórica violação de direitos e violência institucional no SUS e aponta para a qualificação do trabalho que tem impactado os serviços de Macaé, da região e do estado do Rio de Janeiro. Para as/os profissionais inseridas/os nesse processo, o atendimento realizado ganha ainda mais importância.

Na fala da P1 fica explícita a ausência de atendimento à população LGBT em Macaé e no entorno. Em algumas passagens dos relatos expostos, 
muitas vezes é citado o projeto Consultório LGBT como uma experiência oposta a um quadro nacional/regional/local de violação direitos e violência no âmbito dos serviços de saúde. $\bigcirc$ projeto expressa a possibilidade de atendimento respeitoso e para além do estigma, o que de fato deveria ocorrer em todos os serviços que atendem a população LGBT.

\section{Considerações finais}

O Consultório LGBT ampliou o leque de intervenção no município, não apenas na questão ambulatorial, mas promovendo ações que podem dialogar com toda a população e com outros espaços na construção de uma sociabilidade não LGBTfóbica. Também foi possivel, em menos de três anos, estabelecer uma rede com o Centro Especializado de Atendimento à Mulher (Ceam), com o Instituto Estadual de Diabetes e Endocrinologia (IED), com o Hospital Universitário Pedro Ernesto (único no estado do Rio de Janeiro habilitado a realizar cirurgias de redesignação sexual), com a Área Técnica de Prevenção e Controle do Tabagismo e o programa de ISTs/aids de Macaé.

É a tentativa de oferecer o trabalho diferenciado daquele que as/os usuárias/os denunciam receber em outros espaços de saúde na cidade. Trata-se de um trabalho pautado naquilo que é prezado na própria PNS-LGBT.

A formação continuada é urgente para todalos as/os profissionais, se de fato queremos construir ações capazes de combater a LGBTfobia. Em nossas análises, o preconceito e o desconhecimento por parte de profissionais diante das demandas de usuárias/os LGBT aparecem como determinantes para a descontinuidade do tratamento de pessoas LGBTs em serviços de saúde. As entrevistas com usuárias/os e profissionais evidenciam este despreparo, seja na rede pública ou privada de saúde no município de Macaé.

A perpetuação de uma sociabilidade que incentiva a não reflexão crítica do trabalho, a desumanização e que sucateia cada vez mais a formação acadêmica influencia diretamente o aumento de ações de cunho discriminatório e violento. Essa preocupação se faz ainda maior na conjuntura em que o Brasil está inserido, um contexto marcado por forte regressão dos direitos humanos e ofensiva conservadora.

Experiências como a do projeto Consultório LGBT, realizada por profissionais do Consultório na Rua de Macaé (RJ), contrapõem a histórica privação de direitos nos serviços de saúde à população LGBT, podendo servir de espelho para a construção de novas formas de atendimento no SUS e no sistema privado de saúde, que possibilitem a materialização da PNS-LGBT 
e o combate à violência estrutural e também institucional. Trata-se de criar mais espaços de discussão e qualificação profissional sobre gênero e sexualidade, com uma rede de serviços de referência para população LGBT numa tentativa de impactar as outras áreas e políticas sociais, assim como promover a articulação com movimentos e iniciativas já existentes.

Apesar de todo o esforço das/os profissionais do Consultório LGBT, sabemos que isso ainda não é suficiente. Algumas questões podem ser pontuadas e problematizadas, como a subnotificação formal dos casos de violência contra LGBTs nos serviços de saúde de Macaé, denunciada pelas/ os usuárias/os de forma a exigir da prefeitura uma intervenção - seja promulgando uma normativa local que ampare esses atendimentos ou suscitando espaços de debate, atualização profissional e educação permanente que discutam temáticas de sexualidade e identidade de gênero.

$\bigcirc$ esforço individual dos/as profissionais é limitado para construir um cenário de enfrentamento à LGBTfobia. É necessário envolvimento público, com recursos e mobilização política, incluindo sujeitos LGBTs e movimentos organizados, para pressionar o Estado pela construção de políticas públicas, assim como participação das universidades produzindo conhecimento e debatendo essas questões nos currículos.

\section{Referências}

ALMEIDA, G. Identidade de gênero com ênfase nas pessoas trans: particularidades e acesso à saúde, trabalho e educação. In: NOGUEIRA, L. et al. (org.). Hasteemos a bandeira colorida. São Paulo: Expressão Popular, 2018. p. 159-186.

ARAÚJO, M. A. L. et al. Relação usuária-profissional de saúde: experiência de uma mulher homossexual em uma unidade de saúde de referência de Fortaleza. Escola Anna Nery, Rio de Janeiro, v. 10, n. 2, p. 323-327, 2006. Disponivel em: https://bit.ly/2YS2ndU. Acesso em: 30 jun. 2020.

CISNE, M. Gênero, divisão sexual do trabalho e serviço social. São Paulo: Outras Expressões, 2012.

BRASIL. Ministério da Saúde. Portaria n 1.820, de 13 de agosto de 2009. Disponivel em: https://bit.ly/2NOvBnD. Acesso em: 30 jun. 2020. 
BRASIL. Ministério da Saúde. Portaria n 2.836, de $1^{\circ}$ de dezembro de 2011. Institui a Política Nacional de Saúde Integral de LGBT. Brasillia, DF. 2011. Disponivel em: https://bit.ly/3guVZPZ. Acesso em: 30 jun. 2020.

BRASIL. Ministério da Saúde. Política Nacional de Saúde LGBT. Brasillia, DF, 2013. Disponivel em: https://bit.ly/2AqfkIS. Acesso em: 30 jun. 2020.

CARNEIRO, A. A morte da clínica: movimento homossexual e luta pela despatologização da homossexualidade no Brasil (1978-1990). In: SIMPÓSIO NACIONAL DE HISTÓRIA, 28., 2015, Florianópolis. Anais [...]. Florianópolis: ANPUH, 2015. p. 1-15.

CARVALHO, M.; CARRARA, S. Em direção a um futuro trans? Contribuição para a história do movimento de travestis e transexuais no Brasil. Sexualidad, Salud y Sociedad, Rio de Janeiro, n. 14, p. 319-351, 2013.

CASSIN, M. P. S. As políticas sociais nos governos do PT e a consolidação da hegemonia burguesa no Brasil. In: SIMPÓSIO MINEIRO DE ASSISTENTES SOCIAIS, 4., 2016, Belo Horizonte. Anais [...]. Belo Horizonte: CRESS-MG, 2016. p. 1-14. Disponivel em: https://bit.ly/3f51kgB. Acesso em: 30 jun. 2020.

CFESS. Série assistente social no combate ao preconceito: o que é preconceito? Caderno 1. Brasilia, DF, 2016a. Disponivel em: https://bit.ly/3gISafU. Acesso em: 30 jun. 2020.

CFESS. Série assistente social no combate ao preconceito: o que é transfobia? Caderno 4. Brasilia, DF, 2016b. Disponivel em: https://bit.ly/3glSafU. Acesso em: 30 jun. 2020.

FACCHINI, R.; FRANÇA, I. L. De cores e matizes: sujeitos, conexões e desafios no Movimento LGBT brasileiro. Sexualidad, Salud y Sociedad, Rio de Janeiro, n. 3, p. 54-81, 2009.

FONTENELE, D. F.; REIS, P. R.; FRIAS, K. M. M. M. Gênero, sexualidade e preconceito: a importância do debate LGBTTT para a qualidade da assistência em saúde. In: JORNADA INTERNACIONAL DE POLÍTICAS PÚBLICAS, 7., 2015, São Luís. Anais [...]. São Luís: Universidade Federal do Maranhão, 2015. 
HAMERMULLER, A. Estudo avalia efeitos de programa de intervenção para mudar atitudes de profissionais da saúde em relação a LGBTs. UFRGS Ciência. 2016. Disponivel em: https://bit.ly/2ZmDJB2. Acesso: 30 jun. 2020.

IBGE. Censo demográfico. Rio de Janeiro, 2010. Disponivel em: https://bit.ly/ 3gaR2eS. Acesso em: 30 jun. 2020.

HOFFMAN, B. Com Lula e Dilma, direitos LGBT conquistam resultados inéditos. Notícias do PT. 2016. Disponível em: https://bit.ly/2YSGivP. Acesso em: 30 jun. 2020.

MELLO, L.; BRITO, W.; MAROJA, D. Políticas Públicas para população LGBT no Brasil: notas sobre alcances e possibilidades. Cadernos Pagu, Campinas, v. 39, p. 403-429, 2012.

POPADIUK, G. S.; OLIVEIRA, D. C.; SIGNORELLI, M. C. A PNS-LGBT e o acesso ao Processo Transexualizador no Sistema Único de Saúde (SUS): avanços e desafios. Ciência \& Saúde Coletiva, Rio de Janeiro, v. 22, n. 5, p. 1509-1520, 2017.

RIBEIRO, D. Stonewall: 40 anos de luta pelo reconhecimento LGBT. In: COLLING, L. (org.). Stonewall 40 + o que no Brasil? Salvador: EDUFBA, 2011. 153-157.

TOLEDO, J. R. O conservadorismo vai à faculdade. Piauí, 2018. Disponível em: https://bit.ly/3iisulU. Acesso em: 30 jun. 2020.

Recebido em abril de 2020.

Aprovado em junho de 2020. 